\title{
p21 participates in the regulation of anaplastic thyroid cancer cell proliferation by miR-146b
}

\author{
SHIYANG WANG, YANGJING CHEN and YANXIA BAI \\ Department of Otorhinolaryngology - Head and Neck Surgery, The First Affiliated Hospital, \\ Xi'an Jiaotong University, Xi'an, Shaanxi 710061, P.R. China
}

Received April 21, 2015; Accepted May 18, 2016

DOI: $10.3892 / \mathrm{ol} .2016 .4874$

\begin{abstract}
Anaplastic thyroid carcinoma (ATC) originates from completely undifferentiated cells, and is the most lethal type of thyroid-derived tumor. Numerous microRNAs have significant roles in tumorigenesis by targeting relevant genes. The role of microRNA $146 \mathrm{~b}$ (miR-146b) in ATC remains to be elucidated. In order to characterize the role of miR-146b in ATC, overexpression or interference of miR-146b was induced in ATC cell lines, and cell proliferation and migration were evaluated. The potential targets of miR-146b were searched in the Gene Expression Omnibus database for ATC and matched non-tumor control samples. The expression level of potential targets was detected following overexpression or interference of miR-146b in ATC cell lines. In the present study, cell proliferation was promoted when overexpression of miR-146b was induced in ATC, and inhibited when interference of miR-146b was induced, which indicated that miR-146b affects the proliferation of ATC cells in vitro. In addition, cell migration of ATC was also affected by miR-146b. During the search for potential targets of miR-146b in ATC, $p 21$ (also known as $p 21^{\text {Wafl/Cipl }}$ or $C D K N 1 A$ ) was noted for its role in cell cycle progression and tumor pathogenesis. The expression level of p21 was influenced by the level of miR-146b, and the results of the present study demonstrated that the level of p21 was increased when FRO cells were transformed with miR-146b mimic, and p21 was downregulated when FRO cells transformed with anti-miR-146b. In conclusion, p21 may participate in the regulation of ATC cell proliferation by miR-146b.
\end{abstract}

Correspondence to: Dr Yanxia Bai, Department of Otorhinolaryngology - Head and Neck Surgery, The First Affiliated Hospital, Xi'an Jiaotong University, 277 West Yanta Road, Xi'an, Shaanxi 710061, P.R. China

E-mail: yanxiab@126.com

Key words: anaplastic thyroid carcinoma, cell proliferation, oncogenesis, microRNA-146b, p21

\section{Introduction}

Thyroid cancers are the most common malignancy of endocrine organs (1). There were 62,980 estimated new cases of thyroid cancer in the United States in 2014, as well as 1,890 cancer-associated mortalities (2). The frequency of ATC is increasing, and it currently accounts for $2.5 \%$ of all cancers in the United States (3). Thyroid cancer has become a particular research focus as it encompasses several histopathological tumor types with distinct levels of differentiation (4). Thyroid carcinomas originate from follicular and parafollicular cells $(5,6)$, and are subdivided into well-differentiated papillary thyroid carcinoma (PTC) and follicular thyroid carcinoma (FTC), poorly differentiated carcinoma (PDC), and completely undifferentiated anaplastic thyroid carcinoma (ATC) (4). ATC is responsible for $1.7 \%$ of all thyroid cancer cases, however, is the most deadly of the thyroid-derived tumors, with patients demonstrating a median survival time of 5 months and a $20 \%$ 1-year survival rate $(3,7)$.

MicroRNAs (miRs) are a class of endogenous noncoding RNAs, which act as negative regulators of gene expression (8). Previous studies have indicated that a large number of miRs are involved in almost every major cellular function, including the process of oncogenesis (8-10). miRs may play roles as tumor suppressors or oncogenes (11). The expression profiles of miRs have been characterized in various histopathological types of thyroid cancer, and a series of miRs exhibited differential expression patterns (4). A series of miRs have significant roles in ATC and their targets have been validated, for example, miR-20a was upregulated in ATC and targets LIM domain kinase 1 (12). Additionally, miRs were considered as potential diagnostic markers for thyroid carcinoma $(13,14)$.

The expression of miR-146b in various types of thyroid carcinoma has been summarized previously $(15,16)$. Its expression was markedly increased in PTC and PDC and slightly increased in FTC $(15,16)$; however, expression levels were not consistent between various studies that investigated expression in ATC. Visone et al (17) and Braun et al (18) reported no significant change in the expression levels of miR-146b $(\mathrm{P}<0.05)$ in ATC. However, Nikiforova et al (4) reported that miR-146b was upregulated in ATC compared with hyperplastic nodules, and Fassina et al (19) reported that miR-146b was upregulated in ATC compared with primary 
thyroid lymphoma and multinodular goiter (19). Therefore, the role of miR-146b in ATC remains to be fully elucidated.

p21 encodes a protein that binds to and inhibits the activity of cyclin-dependent kinase 2 (CDK2) or CDK4 complexes, and functions as a regulator of cell cycle progression at G1. $p 21$ is the target of tumor suppressor protein p53 or its isoform $(20,21)$, and thus functions as a tumor suppressor in a variety of types of cancer (22). It has been observed that p21 is regulated by a variety of miRs during the promotion of progression of the cell cycle or tumor growth, including miR-106b (11), miR-17 (23), miR-224 (24) and miR-663 (25).

In the present study, the effect of miR-146b on proliferation was investigated in ATC cells, and the potential targets of miR-146b were searched. It was concluded that miR-146b may influence ATC proliferation through regulation of $\mathrm{p} 21$.

\section{Materials and methods}

Ethics statement. The present study was approved by The Ethics Committee of the First Affiliated Hospital, Medical School of Xi'an Jiaotong University (Xi'an, China), and no human/animal tissues were used in the present study.

miR profile data collection and analysis. $\mathrm{miR}$ profile data of ATC and matched non-tumor controls were collected from the Gene Expression Omnibus (GEO) database (www.ncbi.nlm. nih.gov/gds; GSE29265). During the study, 10 ATC samples and 10 patient-matched non-tumor samples were utilized for additional miR analysis. The comparison of miR profiles between 10 ATC and 10 non-tumor samples was performed by studying the fold change and using the Stuent's $t$-test method on the Limma package on $\mathrm{R}$ software version 3.0.3 (www.r-project.org). The cutoff for a significantly differentially expressed miR was fold change $>2$ and $\mathrm{P}<0.05$.

Cell line. The FRO human anaplastic thyroid cancer cell line has been described and authenticated previously (26). The FRO cell line was maintained in RPMI-1640 medium (Thermo Fisher Scientific, Inc., Waltham, MA, USA) and $10 \%$ fetal bovine serum (FBS; Thermo Fisher Scientific, Inc.) at $37^{\circ} \mathrm{C}$ in an atmosphere of $5 \% \mathrm{CO}_{2}$.

Cell transfection. FRO cells were seeded at $3 \times 10^{5}$ cells/wells into 6-well plates and incubated overnight at $37^{\circ} \mathrm{C}$. Transfection of miR-146b mimic, the anti-miR-146b, inactive control cel-miR-67 (Dharmacon; GE Healthcare Life Sciences, Chalfont, UK) or pMIR-Report vectors (Invitrogen; Thermo Fisher Scientific, Inc.) was performed with Lipofectamine $2000^{\circledR}$ transfection reagent (Invitrogen; Thermo Fisher Scientific, Inc.) using $300 \mathrm{nmol}$ of miR or $1 \mu \mathrm{g} / \mathrm{ml}$ DNA plasmid, respectively.

Cell proliferation. Cell proliferation assays were performed using a Cell Counting Kit-8 (CCK-8; Dojindo Molecular Technologies, Inc., Kumamoto, Japan). FRO cells were seeded into 24-well plates at $2 \times 10^{5}$ cells/well. Cells were incubated at $37^{\circ} \mathrm{C}$ in $10 \%$ CCK-8 reagent, which was diluted in fresh Dulbecco's modified Eagle's medium (Thermo Fisher Scientific, Inc.). Cell proliferation was measured by microplate reader scanning at $450 \mathrm{~nm}$ according to the manufacturer's protocol. Cell proliferation rates were determined at $0,24,48$ and $72 \mathrm{~h}$ following transfection.
Table I. Differentially expressed target genes of microRNA-146b in anaplastic thyroid carcinoma.

\begin{tabular}{lccl}
\hline Gene & $\log \mathrm{FC}$ & $\mathrm{P}$-value & Identification method \\
\hline 21/CDKN1A & -1.39 & $<0.001$ & Reporter assay \\
MMP16 & 1.91 & $<0.001$ & Reporter assay \\
KLF7 & -0.87 & $<0.001$ & Predicted \\
\hline
\end{tabular}

CDKN1A, cyclin-dependent kinase inhibitor 1A; MMP16, matrix metalloproteinase-16; KFL7, Kruppel-like factor 7. FC, fold change.

Migration assays. Cell migration assays were performed using a Transwell chamber (Corning Incorporated, Corning, NY, USA) with or without Matrigel (Invitrogen; Thermo Fisher Scientific, Inc.). In the Transwell assay, FRO cells 24, 48 or $72 \mathrm{~h}$ subsequent to transfection, were trypsinized and seeded into chambers at a density of $8 \times 10^{4}$ cells/well and cultured in RPMI-1640 medium with $2 \%$ FBS, while $600 \mathrm{ml}$ $10 \%$ FBS RPMI-1640 was added to the lower chamber. Following incubation at $37^{\circ} \mathrm{C}$ in an atmosphere of $5 \% \mathrm{CO}_{2}$ for $24 \mathrm{~h}$, migrated cells were fixed with $100 \%$ methanol for $30 \mathrm{~min}$. Non-migrated cells were removed using cotton swabs. Subsequently, cells on the bottom surface of the membrane were stained by $0.1 \%$ crystal violet (Invitrogen; Thermo Fisher Scientific, Inc.) for $20 \mathrm{~min}$. Cell images were obtained under a phase-contrast microscope (Olympus Corporation, Tokyo, Japan).

Western blotting. FRO cells were lysed with radioimmunoprecipitation assay buffer (Thermo Fisher Scientific, Inc.) containing a mixture of protease inhibitors from the Clean-Blot ${ }^{\mathrm{TM}}$ IP Detection kit (Thermo Fisher Scientific, Inc.) for $30 \mathrm{~min}$. The lysates were subsequently centrifuged at $4^{\circ} \mathrm{C}$ and $8,050 \mathrm{x} g$ for $15 \mathrm{~min}$. The protein concentrations were determined by bicinchoninic acid protein assay kit (Thermo Fisher Scientific, Inc.), according to the manufacturer's protocol. The proteins were boiled at $95^{\circ} \mathrm{C}$ for $5 \mathrm{~min}$ and subsequently stored at $-70^{\circ} \mathrm{C}$. A total of $50 \mu \mathrm{g}$ protein was electrophoresed on $10 \%$ sodium dodecyl sulfate-polyacrylamide gels and transferred onto polyvinylidene difluoride (PVDF) membranes. Subsequently, PVDF membranes were blocked for $1 \mathrm{~h}$ in $5 \%$ non-fat milk at room temperature. Membranes were probed with rabbit anti-human anti-p21 primary antibodies (catalog no., ab109199, Abcam, Cambridge, MA, USA) at a dilution of $1: 100$ at $4^{\circ} \mathrm{C}$ overnight, followed by three washes with Tris-buffered saline and Tween 20 (TBST). Goat anti-rabbit immunoglobulin G horseradish peroxidase-conjugated secondary antibodies (catalog no., ab6721; Abcam) were added at a dilution of 1:2,000, and incubated for $1 \mathrm{~h}$ at room temperature. Following incubation, the membranes were washed three times with TBST and enhanced chemiluminescence was used for detecting antigens on X-ray film. $\beta$-actin (Immunocreate, LLC, Birmingham, AL, USA) was used as a loading control. The fold changes in gene expression were calculated by the equation $2^{-\Delta \Delta \mathrm{Cq}}(27)$.

Statistical analysis. Data are presented as the mean \pm standard deviation. Differences between groups were assessed using the 
A
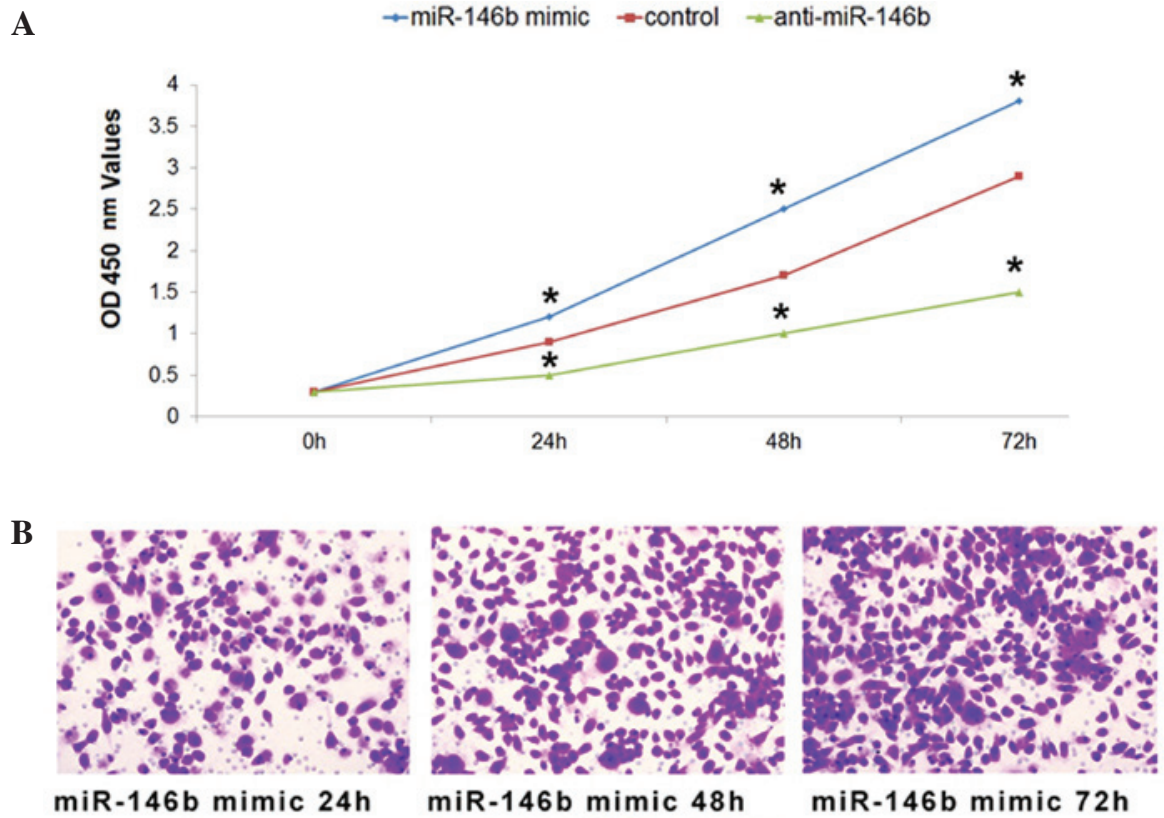

C

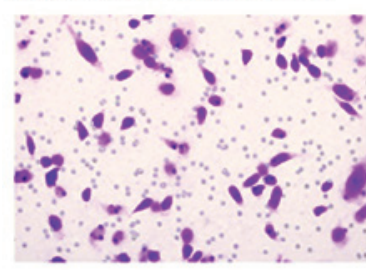

miR-146b mimic $48 \mathrm{~h}$

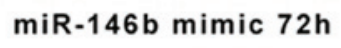

anti-miR-146b $24 \mathrm{~h}$

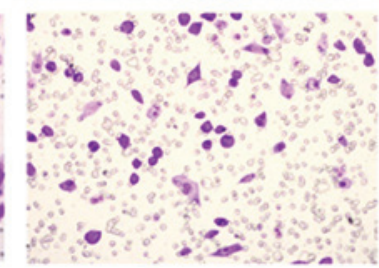

anti-miR-146b $48 \mathrm{~h}$

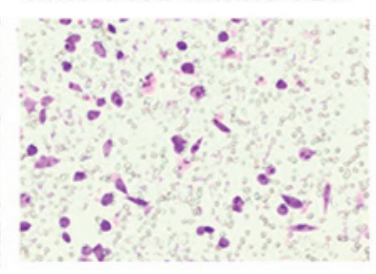

anti-miR-146b $72 h$

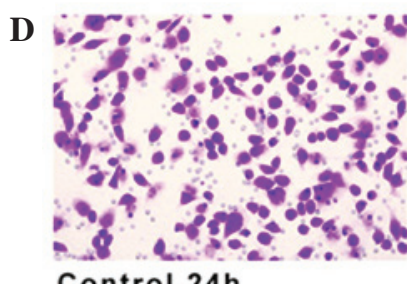

Control 24h
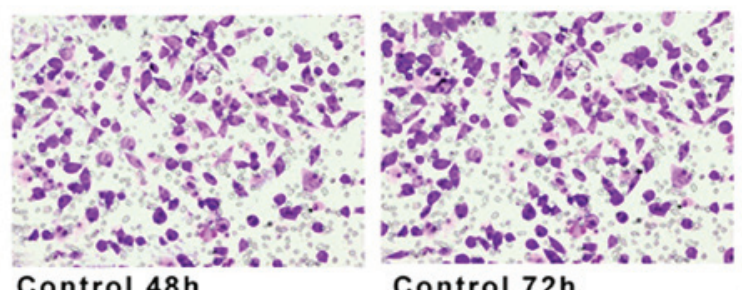

Figure 1. Proliferation and migration of the ATC FRO cell line following overexpression or interference of miR-146b. (A) Growth of the human ATC FRO cell line following transfection with miR-146b mimics, anti-miR-146b or inactive control cel-mir- 67 at $0,24,48$ and $72 \mathrm{~h}$ subsequent to transfection. The proliferation of FRO cells was assessed through the detection of absorbance at $450 \mathrm{~nm}$ following a cell counting kit- 8 assay. " $\mathrm{P}<0.05$ compared with the control (B) Representative images of migrated FRO cells 24,48 and $72 \mathrm{~h}$ subsequent to transfection with miR-146b mimics. (C) Representative images of migrated FRO cells 24, 48 and $72 \mathrm{~h}$ subsequent to transfection with anti-miR-146b. (D) Representative images of migrated FRO cells 24,48 and $72 \mathrm{~h}$ subsequent to transfection with inactive control cel-mir-67. ATC, anaplastic thyroid carcinoma; miR, microRNA; OD, optical density.

Student's $t$-test. $\mathrm{P}<0.05$ was considered to indicate a statistically significant difference. Statistical analysis was performed on R version 3.0.3 (www.r-project.org).

\section{Results}

miR-146b affects the proliferation and migration of ATC cells in vitro. To investigate the effects of miR-146b on the proliferation of ATC cells, miR-146b mimic, anti-miR-146b or inactive cel-mir-67 (control) was transfected into the FRO human ATC cell line as previously described (26). The optical density at $450 \mathrm{~nm}$ was measured 0, 24, 48 and $72 \mathrm{~h}$ subsequent to transfection as an indicator of active cell number. As a result of miR-146b overexpression following transfection of synthetic miR-146b RNA duplexes, the cell proliferation rate increased compared with the control at $24 \mathrm{~h}$ after transfection, and demonstrated a higher proliferation rate at 48 and $72 \mathrm{~h}$ (Fig. 1A). Furthermore, FRO cell proliferation was inhibited when miR-146b was downregulated compared with the control (Fig. 1A). Therefore, the results of the present study indicated that miR-146b influenced the proliferation of ATC cells.

Furthermore, the migration of FRO cells was investigated following transfection with miR-146b mimic, anti-miR-146b or inactive cel-mir-67. Compared with the negative control, the migration of FRO cells was promoted by transfection with miR-146b mimic (Fig. 1B), and inhibited by transfection with anti-miR-146b (Fig. 1C). Taken together, the results of the present study indicate that miR-146b exhibited a function in cell proliferation and migration of ATC cells.

Potential targets of miR-146b in ATC. In order to investigate the potential targets of miR-146b in ATC, the miR profile data of ATC and patient-matched non-tumor controls was searched 

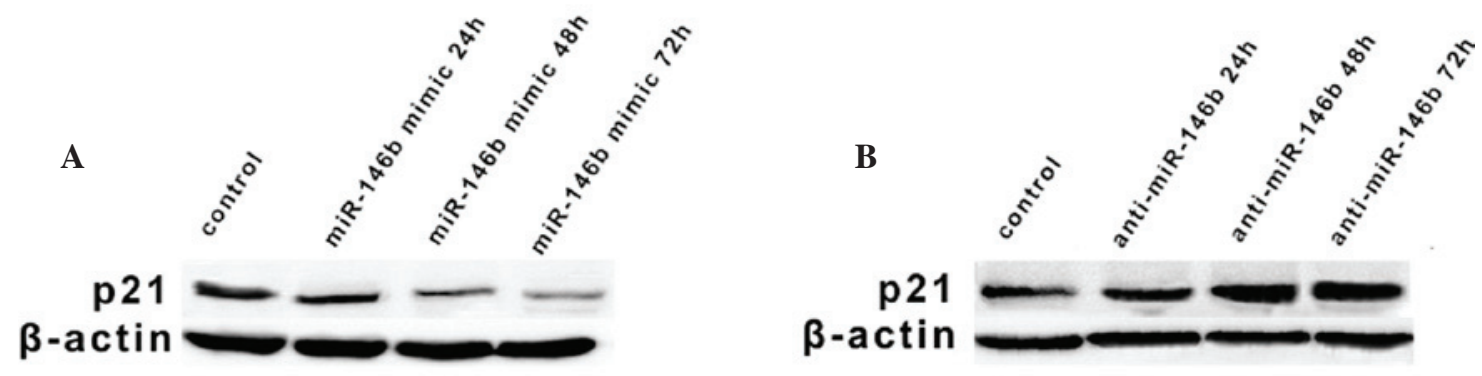

C

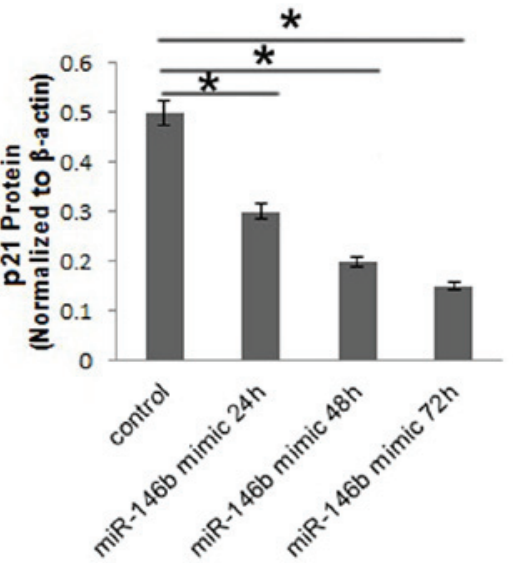

D

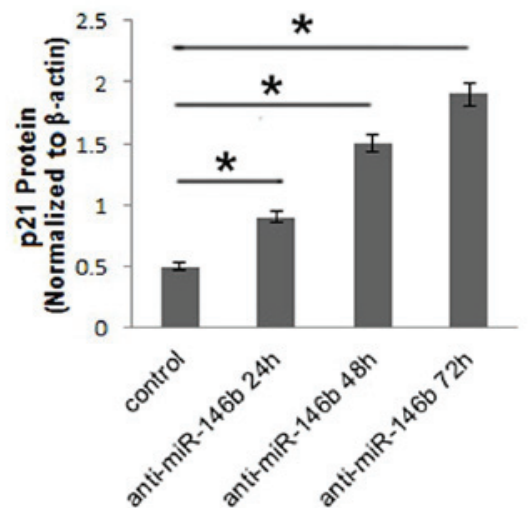

Figure 2. Expression levels of p21 following overexpression or interference of miR-146b. (A) Expression levels of p21 were examined by western blotting following transfection with miR-146b mimic or inactive control cel-mir-67 at 24, 48 and $72 \mathrm{~h}$ subsequent to transfection. (B) Expression levels of p21 were examined by western blotting following transfection with anti-miR-146b or inactive control cel-mir- 67 at 24,48 and $72 \mathrm{~h}$ subsequent to transfection. (C) Quantification of expression levels of p21 examined by western blotting following transfection with miR-146b mimic or inactive control cel-mir-67 at 24,48 and $72 \mathrm{~h}$ subsequent to transfection. ${ }^{*} \mathrm{P}<0.01$. (D) Quantification of expression levels of $\mathrm{p} 21$ examined by western blotting following transfection with anti-miR-146b or inactive control cel-mir- 67 at 24,48 and $72 \mathrm{~h}$ subsequent to transfection. " $\mathrm{P}<0.01$. $\beta$-actin was used as a loading control. miR, microRNA.

online in the GEO database (www.ncbi.nlm.nih.gov/gds; GSE29265). Comparison of miR profiles in this database was performed through fold change and t-test methods. In total, 215 differentially-expressed genes were obtained. Out of these identified genes, $p 21$ was focused on as it has been proven to be a tumor suppressor targeted by p53 in a variety of types of cancer (22). Compared with non-tumor controls, the expression of p21 was significantly downregulated in ATC samples (log fold change $<-1 ; \mathrm{P}=0.0039$; Table I). Therefore, the hypothesis that miR-146b regulates ATC proliferation through $p 21$ was proposed and further investigated.

miR-146b influences the expression of 21 in the FRO ATC cell line. As miR-146b had an effect on cell proliferation in ATC cells and p21 was downregulated in ATC cells, the present study aimed to determine whether miR-146b influenced ATC cell proliferation via modulation of $p 21$. The protein expression of p21 in FRO cells was investigated using western blotting following transfection with miR-146b mimic, anti-miR-146b or inactive cel-mir-67. The protein level of p21 was downregulated $24 \mathrm{~h}$ subsequent to infection with miR-146b mimic, and then decreased continuously, while $72 \mathrm{~h}$ subsequent to infection, it was $\sim 30 \%$ of that observed in the control (Fig. 2A and B). Furthermore, when the FRO cell line was infected with anti-miR-146b, the protein level of p21 was upregulated gradually at 24 and 48, and subsequently increased 3.8-fold compared with the control at $72 \mathrm{~h}$ (Fig. 2C and D). Based on the results of the present study, it was concluded that miR-146b may influence proliferation of ATC cells via regulation of $\mathrm{p} 21$.

\section{Discussion}

The role of miR-146b in ATC remains to be elucidated. In order to characterize the role of miR-146b in ATC, miR-146b was transfected into ATC cell lines and its impact on cell proliferation and migration was investigated. In addition, the potential mechanisms underling these phenomena were also investigated.

In the present study, the role of miR146b in the proliferation of ACT cells was described, and evidence to support the participation of $p 21$ in this process was presented. $p 21$, also known as Ras, is a potent cyclin-dependent kinase inhibitor, which has an important role in cancer (28). The mechanism in which Ras ${ }^{\mathrm{G} 12 \mathrm{~V}}$ induces the arrest of cell growth serves as a fail safe protection from malignant transformation (29). During this process in human mammary epithelial cells, p21 was previously shown to be regulated by a series of miRs, including miR-106b, miR-130b, miR-302a, miR-302b, miR-302c, miR-302d, miR-512-3p and miR-515-3p, while miR $146 \mathrm{a}$ and miR-146b demonstrated a relatively weak rescue from $\mathrm{Ras}^{\mathrm{G} 12 \mathrm{~V}}$-induced senescence (30). There is robust evidence that p21 is the direct target of miR-106b during promotion of cell cycle progression (11). Though miR-146b exhibited varying seed sequences from miR-106b, the expression level of $p 21$ 
was observed to be regulated by miR-146b in ATC cells in the present study. Therefore, it may be assumed that there is an alternative mechanism that is responsible for the regulation of miR-146b by $p 21$ and its influence on ATC cell proliferation.

In general, the present study revealed that miR-146b promotes ACT cell proliferation and inhibits $p 21$. These findings might improve our understanding on the pathogenesis of ACT and provide potential target for future therapies.

\section{Acknowledgements}

The present study was supported by the Youth Program of the National Natural Science Foundation of China (grant no. 81102056) and the Project of Science and Technology of Social Development in Shaanxi Province (grant no. 2016SF-114).

\section{References}

1. Viola D, Valerio L, Molinaro E, Agate L, Bottici V, Biagini A, Lorusso L, Cappagli V, Pieruzzi L, Giani C, et al: Treatment of advanced thyroid cancer with targeted therapies: Ten years of experience. Endocr Relat Cancer 23: R185-R205, 2016.

2. Likhterov I, Tuttle RM, Haser GC, Su HK, Bergman D, Alon EE, Bernet V, Brett E, Cobin R, Dewey EH, et al: Improving the adoption of thyroid cancer clinical practice guidelines. Laryngoscope: April 14, 2016 (Epub ahead of print).

3. Smallridge RC, Ain KB, Asa SL, Bible KC, Brierley JD, Burman KD, Kebebew E, Lee NY, Nikiforov YE, Rosenthal MS, et al; American Thyroid Association Anaplastic Thyroid Cancer Guidelines Taskforce: American Thyroid Association guidelines for management of patients with anaplastic thyroid cancer. Thyroid 22: 1104-1139, 2012.

4. Nikiforova MN, Tseng GC, Steward D, Diorio D and Nikiforov YE: MicroRNA expression profiling of thyroid tumors: Biological significance and diagnostic utility. J Clin Endocrinol Metab 93: 1600-1608, 2008.

5. Kebebew E: Hereditary non-medullary thyroid cancer: World J Surg 32: 678-682, 2008.

6. Vriens MR, Suh I, Moses W and Kebebew E: Clinical features and genetic predisposition to hereditary nonmedullary thyroid cancer. Thyroid 19: 1343-1349, 2009.

7. Smallridge RC and Copland JA: Anaplastic thyroid carcinoma: Pathogenesis and emerging therapies. Clin Oncol (R Coll Radiol) 22: 486-497, 2010.

8. Azizian A, Gruber J, Ghadimi BM and Gaedcke J: MicroRNA in rectal cancer. World J Gastrointest Oncol 8: 416-426, 2016.

9. Endzelinš E, Melne V, Kalnina Z, Lietuvietis V, Riekstina U, Llorente A and Linē A: Diagnostic, prognostic and predictive value of cell-free miRNAs in prostate cancer: A systematic review. Mol Cancer 15: 41, 2016.

10. Sheu SY, Grabellus F, Schwertheim S, Worm K Broecker-Preuss M and Schmid KW: Differential miRNA expression profiles in variants of papillary thyroid carcinoma and encapsulated follicular thyroid tumours. Br J Cancer 102: 376-382, 2010.

11. Ivanovska I, Ball AS, Diaz RL, Magnus JF, Kibukawa M, Schelter JM, Kobayashi SV, Lim L, Burchard J, Jackson AL, et al: MicroRNAs in the miR-106b family regulate p21/CDKN1A and promote cell cycle progression. Mol Cell Biol 28: 2167-2174, 2008.

12. Xiong Y, Zhang L and Kebebew E: MiR-20a is upregulated in anaplastic thyroid cancer and targets LIMK1. PLoS One 9: e96103, 2014.
13. Chen YT, Kitabayashi N, Zhou XK, Fahey TJ III and Scognamiglio T: MicroRNA analysis as a potential diagnostic tool for papillary thyroid carcinoma. Mod Pathol 21: 1139-1146, 2008.

14. Vriens MR, Weng J, Suh I, Huynh N, Guerrero MA, Shen WT, Duh QY, Clark OH and Kebebew E: MicroRNA expression profiling is a potential diagnostic tool for thyroid cancer. Cancer 118: 3426-3432, 2012.

15. Lodewijk L, Prins AM, Kist JW, Valk GD, Kranenburg O, Rinkes IH and Vriens MR: The value of miRNA in diagnosing thyroid cancer: A systematic review. Cancer Biomark 11: 229-238, 2012.

16. Fuziwara CS and Kimura ET: MicroRNA deregulation in anaplastic thyroid cancer biology. Int J Endocrinol 2014: 743450, 2014.

17. Visone R, Pallante P, Vecchione A, Cirombella R, Ferracin M, Ferraro A, Volinia S, Coluzzi S, Leone V, Borbone E, et al: Specific microRNAs are downregulated in human thyroid anaplastic carcinomas. Oncogene 26: 7590-7595, 2007.

18. Braun J, Hoang-Vu C, Dralle H and Hüttelmaier S: Downregulation of microRNAs directs the EMT and invasive potential of anaplastic thyroid carcinomas. Oncogene 29: 4237-4244, 2010

19. Fassina A, Cappellesso R, Simonato F, Siri M, Ventura L, Tosato F, Busund LT, Pelizzo MR and Fassan M: A 4-MicroRNA signature can discriminate primary lymphomas from anaplastic carcinomas in thyroid cytology smears. Cancer Cytopathol 122: 274-281, 2014.

20. Löhr K, Möritz C, Contente A and Dobbelstein M: p21/CDKN1A mediates negative regulation of transcription by $\mathrm{p} 53$. J Biol Chem 278: 32507-32516, 2003.

21. Rohaly G, Chemnitz J, Dehde S, Nunez AM, Heukeshoven J, Deppert W and Dornreiter I: A novel human p53 isoform is an essential element of the ATR-intra-S phase checkpoint. Cell 122: 21-32, 2005.

22. Gupta R, Dong Y, Solomon PD, Wettersten HI, Cheng CJ, Min JN, Henson J, Dogra SK, Hwang SH, Hammock BD, et al: Synergistic tumor suppression by combined inhibition of telomerase and CDKN1A. Proc Natl Acad Sci USA 111: E3062-E3071, 2014.

23. Minami Y, Kohsaka S, Tsuda M, Yachi K, Hatori N, Tanino M, Kimura T, Nishihara H, Minami A, Iwasaki N and Tanaka S: SS18-SSX-regulated miR-17 promotes tumor growth of synovial sarcoma by inhibiting p21WAF1/CIP1. Cancer Sci 105: 1152-1159, 2014.

24. Wang H, Zhu LJ, Yang YC, Wang ZX and Wang R: MiR-224 promotes the chemoresistance of human lung adenocarcinoma cells to cisplatin via regulating $\mathrm{G}_{1} / \mathrm{S}$ transition and apoptosis by targeting p21(WAF1/CIP1). Br J Cancer 111: 339-354, 2014.

25. Yi C, Wang Q, Wang L, Huang Y, Li L, Liu L, Zhou X, Xie G, Kang $\mathrm{T}$, Wang $\mathrm{H}$, et al: MiR-663, a microRNA targeting p21(WAF1/CIP1), promotes the proliferation and tumorigenesis of nasopharyngeal carcinoma. Oncogene 31: 4421-4433, 2012.

26. Schweppe RE, Klopper JP, Korch C, Pugazhenthi U, Benezra M, Knauf JA, Fagin JA, Marlow LA, Copland JA, Smallridge RC and Haugen BR: Deoxyribonucleic acid profiling analysis of 40 human thyroid cancer cell lines reveals cross-contamination resulting in cell line redundancy and misidentification. J Clin Endocrinol Metab 93: 4331-4341, 2008.

27. Livak and Schmittgen: Analysis of relative gene expression data using real-time quantitative PCR and the $2-\Delta \Delta \mathrm{Ct}$ method. Methods 25: 402-408, 2001.

28. Abbas T and Dutta A: p21 in cancer: Intricate networks and multiple activities. Nature Review Cancer 9: 400-414, 2009.

29. Shaw RJ and Cantley LC: Ras, PI(3)K and mTOR signalling controls tumour cell growth. Nature 441: 424-430, 2006.

30. Borgdorff V, Lleonart ME, Bishop CL, Fessart D, Bergin AH, Overhoff MG and Beach DH: Multiple microRNAs rescue from Ras-induced senescence by inhibiting p21(Waf1/Cip1). Oncogene 29: 2262-2271, 2010. 